\title{
VISUAL P3A IN MALE SUBJECTS AT HIGH RISK FOR ALCOHOLISM
}

Authors: Socorro Rodríguez Holguín, Bernice Porjesz, David B. Chorlian, John Polich, and Henri Begleiter

This is the peer reviewed version of the following article Rodríguez Holguín, S., Porjesz, B., Chorlian, D.B., Polich, J. \& Begleiter, H. (1999). Biological Psychiatry, 46, 281-291. doi: 10.1016/S0006-3223(98)00247-9

This article may be used for non-commercial purposes in accordance with Elsevier and Society of Biological Psychiatry terms and conditions for use of self-archived versions. 


\section{Visual p3a in male subjects at high risk for alcoholism}

Authors: Socorro Rodríguez Holguín, Bernice Porjesz, David B. Chorlian, John Polich, and Henri Begleiter

From the Department of Clinical Psychology and Psychobiology, University of Santiago de Compostela, Galicia, Spain (SRH); Department of Psychiatry, State University of New York Health Science Center, Brooklyn, New York (BP, DBC, HB); and the Department of Neuropharmacology, The Scripps Research Institute, La Jolla, California (JP).

Address reprint requests to Bernice Porjesz, PhD, SUNY Health Science Center at Brooklyn, 450 Clarkson Avenue, Box 12031, Brooklyn, NY 11203. 
Background: Voltage of the P300 component of event related potentials (ERPs) has been proposed as a phenotypic marker of risk for alcoholism. P3a elicited by intrusive events is important in the context of deficits in inhibition found during psychophysiological and behavioral evaluations in children of alcoholics.

Methods: ERPs were recorded from a group of adult children of alcoholics (n 5 26) and controls (n 5 23) with a three-stimulus visual oddball paradigm. The task required a difficult perceptual discrimination between a frequent (.80) vertical line and an infrequent (.10) $2^{\circ}$ tilted line (target). An easily discriminable nontarget infrequent horizontal line also occurred (.10). Subjects were required to press a button to the target. P3a was compared using mixed-model ANCOVAs at 31 sites organized in 5 scalp regions. Current source density (CSD) maps were also analyzed.

Results: High-risk (HR) subjects manifested reduced P3a amplitudes compared to controls at frontal, central, parietal, and temporal electrodes. CSD analyses supported these findings with group differences found for all the scalp regions.

Conclusions: The results are discussed in relation to previous HR studies. P3a reductions may be related to deficits in neuronal inhibition during stimulus processing. These results suggest that P3a amplitude may be important as a marker for vulnerability to alcoholism.

Key Words: Alcoholism, high-risk males, visual event related potentials (ERPs), P300, P3a, current source density 


\section{Introduction}

High risk (HR) alcoholism studies attempt to identify genotypic and phenotypic markers that contribute to the etiology of alcoholism by assessing offspring and siblings of alcoholic patients who are genetically vulnerable to the development of the disease (Hesselbrock 1995).

Event-related potentials (ERPs) have been successfully used in HR research, because these neuroelectrical measures relate neurofunctional characteristics with cognitive processes, and different ERP anomalies have been associated with the acute and chronic effects of alcohol intake (see Porjesz and Begleiter 1996 for a review). Some ERP abnormalities of the P300 (P3b) component in alcoholic patients do not recover to normal values after long periods of abstinence (Porjesz and Begleiter 1985; Glenn et al 1993; Parsons 1994). These findings led to the hypothesis that rather than being a consequence of alcoholism, the P300 deficits may precede the development of the disease. Perhaps the most important ERP finding is that low P3s are observed in individuals at risk for alcoholism (offspring of alcoholics) prior to any alcohol exposure (Begleiter et al 1984).

\section{P3b in HR Subjects}

In this context, ERPs have also been used to study genetic influences in HR subjects, because P300 voltage and temporal characteristics are more similar among relatives than unrelated subjects (Polich and Burns 1987; Eischen and Polich 1994; Almasy et al in press) and between monozygotic than dizygotic twins (Rogers and Deary 1991; O'Connor et al 1994a; Katsanis et al 1997; see Van Beijsterveldt and Boomsma 1994 for a review). The P3b ERP component has been used most often in HR studies. It is a positive-going wave with a maximum centroparietal peak occurring between 300 and $600 \mathrm{msec}$ after the stimulus in normal subjects and is thought to be related to the stimulus significance (subjective probability, stimulus meaning, and information transmission) more than to its physical properties (Donchin et al 1986; Johnson 1986).

The first report assessing ERPs in children of alcoholics found that the P3b waves of these subjects were more sensitive than those of control subjects to the acute effects of ethanol (Elmasian et al 1982). A major seminal study found that young children of alcoholics without experience with alcohol consumption and in the absence of an alcohol challenge demonstrated P3b amplitude reductions from a difficult visual-stimulus task similar to those reported from chronic abstinent alcoholics (Begleiter et al 1984). This finding has been subsequently observed using a variety of visual paradigms in children (Whipple et al 1988; Whipple et al 1991; Berman et al 1993a; Hill and Steinhauer 1993) and in young adult males (O'Connor et al 1986, 1987, 1994b; Porjesz and Begleiter 1990; Hesselbrock et al 1993; Cohen et al 1997). Other studies have not found significant differences between HR and control subjects (Whipple and Noble 1986; Polich et al 1988b; Rodríguez Holguín et al 1998b), with suggestions that different risk factors, such as antisocial personality disorder, also may contribute to ERP differences between HR and control subjects (Bauer et al 1994a, b). Several of these later studies, however, have reported longer latencies in the children of alcoholics (Whipple and Noble 1986; Whipple et al 1991). For auditory ERP studies of alcoholic patients and HR subjects results are less consistent, with some reports finding lower P3b voltage in HR subjects (Begleiter et al 1987; Steinhauer and Hill 1993; Benegal et al 1995; Ramachandran et al 1996; Sharma et al 1997) and others obtaining no differences with controls (Polich and Bloom 1986, 1987; Baribeau et al 1987; Steinhauer et 
al1987; Polich et al 1988a; Hill et al 1990; Bauer et al 1994a; Rodríguez Holguín et al 1998b). In a meta-analysis of the P3b ERP studies on HR males, several factors were identified that appear to contribute to the discrepancies among reports. These include subject age, task difficulty, and stimulus sensory modality, with diminished P3b amplitudes most consistently observed when younger (,17 years) subjects were assessed using difficult visual tasks (Polich et al 1994). Additional considerations implicate the lack of agreement in sample selection definition with respect to the criteria and methods employed to diagnose paternal alcoholism, the number of alcoholic relatives required for inclusion, the assessment procedures used, the presence or absence of other psychiatric problems, and the age range of the selected samples (Begleiter and Porjesz 1995). Given these qualifications and despite the absence of total unanimity across HR reports, it is reasonable to conclude that the $\mathrm{P} 3 \mathrm{~b}$ is a valuable candidate to consider as a phenotypic marker for the development of alcoholism. This conclusion is also supported by ERP studies of alcoholics, which have found that the lower $\mathrm{P} 3 \mathrm{~b}$ is associated with a family history of alcoholism more than with alcohol consumption in these patients (Pfefferbaum et al 1991; Cohen et al 1995), and by two recent follow-up reports showing that P3b values in childhood are reasonable predictors of the alcohol and drug consumption in adolescence (Berman et al 1993b; Hill et al 1995).

\section{P3a and Alcoholism}

An important aspect of P300 is that intrusive or "novel" stimuli (e.g., dog barks, abstract color forms, etc.) can produce an earlier, positive potential called "P3a" (Squires et al 1975). P3a is typically larger in amplitude than the P3b over the frontal and central electrode sites and is thought to reflect an alerting process that originates in the frontal cortex (Courchesne et al 1975; Knight 1984). A recent study has demonstrated that stimulus context is a critical determinant for eliciting the P3a component with a three-stimulus oddball paradigm. When an infrequent, nontarget stimulus (not novel) is included in an oddball paradigm, the parietal P3b elicited by the target stimulus is unchanged (Katayama and Polich 1996a, b); however, the infrequent nontarget stimulus does elicit a P300 component that can be manipulated systematically as a function of the stimulus environment or context. When the target/ standard discrimination is easy, the infrequent nontarget elicits a parietal P300 that is smaller in amplitude and longer in latency than the target $\mathrm{P} 3 \mathrm{~b}$, but with a similar scalp topography. When the target/standard perceptual discrimination is difficult, a well-differentiated infrequent nontarget elicits a P3a, larger in amplitude and shorter in latency than P3b at the anterior electrodes, which is similar in morphology to the P3a elicited by novel or unrecognizable stimuli (Katayama and Polich 1998). The theoretical interpretation of these effects is that the context defined by the difficult target/standard discrimination promotes an attentional redirection to the nontarget by means of the frontal lobe activation (Comerchero et al 1997; Comerchero and Polich, 1998, 1999) - a major attribute of the frontal lobe's neurofunctional role (Knight 1996, 1997).

Several studies have attempted to assess P300 components elicited by infrequent nontarget stimuli in alcoholics. Infrequent auditory stimuli in an unattended oddball paradigm elicited reduced P300 amplitude in alcoholics (Realmuto et al 1993). Another report found that alcoholics demonstrated delayed P300 latencies but not reduced amplitudes from the infrequent nontargets in easy three stimulus auditory and visual paradigms (Biggins et al 1995), although both delayed 
latencies and reduced amplitudes were observed in a cocaine and alcohol-codependent group (Biggins et al 1997). More recently, alcoholic and control male subjects were assessed with a difficult visual three-stimulus paradigm, with the alcoholic subjects producing significant reductions in P3a amplitude broadly extended over the scalp (Rodríguez Holguín et al 1999).

Research with offspring of alcoholics is more limited. A sample of young children of alcoholics assessed with an easy three-stimulus visual paradigm obtained reduced P300 in the occipital leads in HR young subjects (Van der Stelt et al 1996). A second study using easy three-stimulus auditory and visual oddball paradigms found that the visual infrequent nontarget stimulus elicited a longer parietocentral P300 latency in the HR male subjects but no differences in amplitude between the groups (Rodríguez Holguín et al 1998a). In sum, P300 differences for alcoholic and HR subjects have been obtained with infrequent nontarget stimuli, although the inter-group effects are not striking.

P3a ERP components elicited in HR individuals by intrusive events are important in the context of behavioral and psychophysiological evaluations of subjects at risk for alcoholism. Behavioral studies have found that children of alcoholics evince a high prevalence of hyperactivity and attention deficit disorder, with higher scores on scales of impulsivity than the general population (Pihl et al 1990; Sher 1991). In addition, male subjects with a multigenerational family history of alcoholism demonstrate normal cardiovascular and electrodermal activity during resting (Finn et al 1990; Newlin and Thomson 1991; Schandler et al 1992) but have been found to be hyperreactive to both aversive (electrical shocks) and neutral (non-aversive tones) novel stimulation (Pihl et al 1989; Finn et al 1990).

Thus, assessment with P3a paradigms may provide useful information about these autonomic indices in HR subjects, because this component reflects the central index of the processing of rare, infrequent events (Knight 1997).

\section{Present Study}

To assess this possibility, the present study employed a difficult perceptual discrimination visual task to evaluate a group of adult HR subjects. An infrequent nontarget stimulus that is perceptually distinct from the target and the standard will elicit a P3a larger in amplitude and shorter in latency than P3b at the frontocentral electrodes (Katayama and Polich 1998; Comerchero and Polich, in press a). In addition, the current source density (CSD) topographic maps were derived to obtain a measure of the sources and sinks of current under the scalp that reflect cortical neural generators. This technique uses Laplacian spline interpolations and constitutes a reference-free measure of brain electrical activity that is independent of any physical conductive head model (Nunez and Pilgreen 1991).

\section{Methods and Materials}

\section{Subjects}

The subjects were 49 adult males ranging from 19 to 30 years of age. Control individuals ( $n=23$, mean $=24.6, \mathrm{SD}=3.2$ years) were recruited through newspaper advertisements or notices posted in the Health Science Center. The initial screening procedure required each subject to complete a questionnaire detailing alcohol and drug use history, and the medical and psychiatric histories for 
both himself and his relatives. Inclusion in the control group depended on both the responses to the questionnaire and required that none of the control candidate's first- or second-degree relatives were diagnosed as alcoholic. The HR group $(n=26$, mean $=22.8$, S.D. $=1.8$ years $)$ consisted of young adult, nonalcoholic males recruited using the same method. The mean age and the years of education in this group were less than in the control group ( $<<.02$ and $\mathrm{p}<.01$, respectively). Inclusion in the HR group required that at least the subject's father be classified as alcohol dependent (DSM-III-R) (mean $=2.4$ alcoholic relatives). Individuals with alcoholic mothers were excluded to rule out fetal alcohol effects. Individuals in the two groups provided informed consent and were paid for their participation. Exclusionary criteria for both the HR and control groups included major medical problems, a current requirement for central nervous system medication, or a history of psychiatric illness and/or drug abuse. Each subject underwent a detailed psychiatric interview focusing on questions of drug histories for both himself and his first- and second-degree relatives. The HR group showed higher alcohol consumption, indicated by the number of drinking days per month $(\mathrm{p}<.0009)$ and by the number of drinks per occasion $(\mathrm{p}<.0027)$.

All subjects were asked to abstain from alcohol for 48 hours before testing, and each was interviewed using the Semi- Structured Assessment for the Genetics of Alcoholism (SSAGA), which uses both DSM-III-R alcohol dependence and Feighner definite criteria for the determination of alcoholism (Bucholz et al 1994). The main demographic characteristics of the sample are summarized in Table 1 . The two groups were reasonably well matched on variables influencing the ERPs, such as the time of the assessment (hour of the day, month), recency of food ingestion, handedness, etc. (Polich and Kok 1995).

\section{Experimental Design}

A 31-lead electrode cap (Electro-Cap International, Inc., Akron, OH) was used to obtain the entire 10-20 International montage with an additional 12 sites also assayed: AF1, AF2, FC1, FC2, FC5, FC6, CP1, CP2, CP5, CP6, PO1, and PO2 (Standard Electrode Position Nomenclature, American Electroencephalographic Society 1991). All scalp electrodes were referred to the nose, and a forehead electrode served as ground. EEG activity was amplified $10 \mathrm{~K}$ using a band-pass $0.02-50$ $\mathrm{Hz}$ (Sensorium EPA-2 Electrophysiology Amplifier, Charlotte, VT), and was sampled at a rate of $256 \mathrm{~Hz}$, with a $125 \mathrm{msec}$ prestimulus baseline and an epoch length of $1375 \mathrm{msec}$. Both vertical and horizontal eye movements were monitored with two electrodes placed supraorbitally and at the outer canthus of the right eye referred to nose. Trials with excessive eye and body movements $(>.73 .3 \mu \mathrm{V})$ were rejected on-line. Digital filtering was performed off-line using a $16 \mathrm{~Hz}$ lowpass filter.

Stimuli were three white lines presented on a black background, one vertical, one tilted $2^{\circ}$ to the right of vertical, and one horizontal. They were presented at the center of a computer monitor with $45 \mathrm{msec}$ duration. The interstimulus interval was $1.6 \mathrm{sec}$, and the stimuli were approximately $8.5 \mathrm{~cm}$ in length. The vertical line was presented with a probability of 0.80 and was designated as the standard stimulus, the $2^{\circ}$ off-vertical line $(0.10)$ was the target and the horizontal line $(0.10)$ was the infrequent nontarget stimulus.

Subjects were seated comfortably in a dimly lighted, temperature regulated, sound-attenuated chamber, and fixated on a centrally displayed point located $1 \mathrm{~m}$ from their eyes on a computer monitor. A brief training sample was run to ensure accurate identification of the target and acceptable task performance. Subjects were instructed to press a button as quickly as possible 
after seeing the line $2^{\circ}$ tilted from vertical. Response speed was emphasized, but not at the cost of accuracy. Response hand side was alternated across subjects, and trials with response time $.1000 \mathrm{msec}$ were automatically excluded from all the analyses. The subjects received a maximum of 350 trials, but the experiment could be terminated when 200 artifact-free trials were acquired (25 of the target and infrequent non-target and 150 of the standard stimuli). ERPs from artifactfree trials were averaged according to stimulus type. Because the major purpose of the present study was to evaluate P3a differences between the subject groups, only ERP data from the infrequent nontarget (P3a) will be presented here.

\section{Data Analysis}

The averaged ERPs were analyzed with a semiautomatic peak detection program. The P3a component was selected as the largest amplitude peak within a time window of 325-550 msec for the infrequent non-target ERPs. Both amplitudes $(\mu \mathrm{V})$ and latencies $(\mathrm{msec})$ were obtained at each of the 31 electrodes from all subjects. Component measurements were organized into five regional groupings: frontal (FP1, FP2, AF1, AF2, Fz, F3, F4, F7, F8), central (FC1, FC2, FC5, FC6, Cz, C3, C4), parietal (CP1, CP2, Pz, P3, P4), temporal (T7, T8, CP5, CP6, P7, P8), and occipital (PO1, PO2, O1, O2). Two-factors mixed model analyses of covariance (ANCOVAs) with risk group as a between-subjects factor and electrode as a within-subjects factor, and using age, drinking days per month, and drinks per occasion as covariates were used to assess group differences in P3a amplitudes and latencies in each of the regions. Greenhouse-Geisser adjustments to the degrees of freedom to correct for violations of sphericity were used where appropriate. ANCOVAs were also used to analyze differences in the ERP measurements for individual electrodes between the two groups. The behavioral data (response time, percentage of correct responses, and false alarms) were assessed using similar ANCOVAs. Bonferronicorrected probabilities were used for all the comparisons.

CSD topographic maps were calculated at the time point of the maximum global field power corresponding to each group (controls $=402 \mathrm{msec}, \mathrm{HR}=430 \mathrm{msec}$ ). The positive values represent sources of current-i.e., a source region where a local radial current is flowing through the skull into the scalp. These procedures have demonstrated previous success at isolating critical neural loci (Gevins et al 1991; Nunez and Pilgreen 1991; Begleiter et al 1993; Chorlian et al 1995; Zhang et al 1997). The topographical maps for high-risk and control subjects were compared. Because the signal to noise ratio in the maps of individuals is too low to permit meaningful comparisons, an averaging procedure must be used to increase the ratio. Because any statistical conclusions on the single average of all subjects in each group can not be drawn, a bootstrap method (Srebro 1996) was modified and used. It is based on the following principle: If the (vectorvalued) members of the group (designated AA) formed by averaging members from group A are statistically similar to the members of the group (designated $\mathrm{BB}$ ) formed by averaging members from group $B$, then the correlations between members of the group (designated $A B$ ) formed by averaging members from the union of $\mathrm{A}$ and $\mathrm{B}$ will be statistically similar to the correlations between members of AA and members of BB. Conversely, if the correlations between members of $\mathrm{AB}$ are statistically dissimilar to those between members of $\mathrm{AA}$ and members of $\mathrm{BB}$, then we can conclude that groups A and B differ. The t-test statistic was used for the comparison between

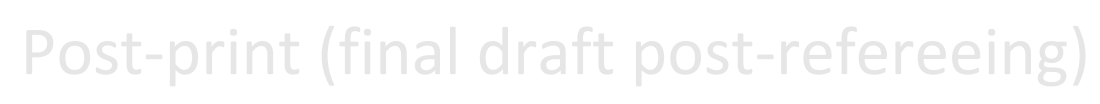


correlations, for both global and regional (frontal, central, parietal, right temporal, left temporal, and occipital).

\section{Results}

\section{Behavioral Performance}

Table 2 summarizes the behavioral data for each subject group. Response times were not significantly different between the groups $(p>.05)$, although there was a tendency for HR subjects to respond more quickly. Percent of correct responses were greater for the HR subjects compared to controls $(F(1,44) 511.9, p<.0017)$, with a tendency for a higher false alarm rate in the HR group that did not reach significance $(p>.05)$.

\section{P3a Amplitude}

Figure 1 illustrates the grand mean waveforms of the ERPs for the control and HR groups. Table 3 summarizes the mean amplitude data and statistical assessment for each electrode.

The mixed-model ANCOVA analyses of the P3a amplitude for the infrequent non-target condition demonstrated significant differences between the two groups in the frontal $(F(1,44)=$ 7.51, $\mathrm{p}<.0088)$, central $(\mathrm{F}(1,44)=9.50, \mathrm{p}<.0033$; parietal $(\mathrm{F}(1,44)=6.60, \mathrm{p}<.0136)$ and temporal $(F(1,44)=6.93, p<.0116)$ regions, but not in the occipital region $(F(1,44)=2.32, p$ $>$.1346). ANCOVA analyses of each individual lead did produce significant reductions for P3a amplitude in the HR group compared to control subjects for six frontal, seven central, five parietal, and four temporal leads (see Table 3).

\section{P3a Latency}

P3a latency was not different between groups for either the regional or the individual ANCOVAs $(p>.05)$.

\section{CSD Topographic Maps}

Figure 2 illustrates the corresponding P3a CSD maps for the control and HR groups. Visual inspection of the maps indicated that the sources of current in the HR group are smaller than in the control group. The HR group produced two frontal sinks that were absent in the control group, but the HR group did not show the occipital and the left temporal sinks present in the control map. Statistical comparison of the two maps (Srebro 1996) demonstrated significant overall differences in the neuroelectric activity between the groups $(\mathrm{t}=45.0, \mathrm{p}<.05)$. Regional comparisons showed that the differences were significant for all the regions $(\mathrm{p}<.05)$.

\section{Discussion}

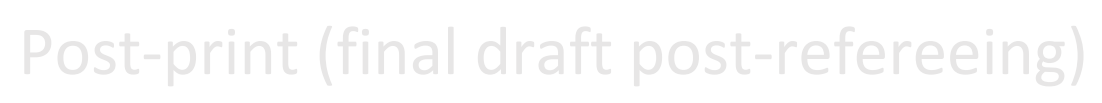


P3a amplitude from the infrequent nontarget stimuli was smaller in subjects at $\mathrm{HR}$ for alcoholism compared to controls. P3a amplitude reductions were significant at frontal central, parietal, and temporal areas, both in the regional and in the individual electrode analyses.

\section{Infrequent Non-Target Stimuli in HR ERP Studies}

Previous studies have used an easy task version of three stimulus paradigms to assess alcoholism in patients (Biggins et al 1995; Biggins et al 1997) and HR subjects (Van der Stelt et al 1996; Rodríguez Holguín et al 1998a). Perceptual discrimination difficulty facilitates P3a generation, with very similar target/standard stimuli and a clearly different infrequent non-target stimulus providing conditions that produce robust P3a components (Katayama and Polich 1998; Comerchero and Polich 1999). The present study elicited a large P3a with greater frontocentral amplitude and shorter latency than $\mathrm{P} 3 \mathrm{~b}$ - a pattern that was not obtained in any of the previous ERP studies on HR subjects. Thus, P3a effects in these reports should be viewed with caution, as the identifying factors of $\mathrm{P} 3 \mathrm{a}$ were not generally observed.

Furthermore, previous HR ERP studies used samples of young children of alcoholics, with an age range from childhood to adolescence. Developmental ERPs elicited by rare nontarget stimuli from children are distinct from those recorded from adults (Courchesne 1977, 1978, 1983), because young subjects do not evince a clear P3a but do produce a parietal positivity similar to P3b with a broad frontal negativity $(\mathrm{Nc})$ around $300-400 \mathrm{msec}$. The frontocentral P3a progressively emerges during adolescence (Courchesne 1977, 1978, 1983). Given these observations, the present ERP waveforms are not comparable to those obtained from studies of young subject samples, which have reported occipital reductions or parietal delays for infrequent nontarget stimuli in HR young males (cf. Van der Stelt et al 1996; Rodríguez Holguín et al 1998a).

\section{Regional Distribution}

Because P3a has a more anterior distribution than P3b, it was expected that the current sources would extend over the parietal, central, and frontocentral areas, anterior to the parietally focused current sources typical in P3b (an example of P3b CSD maps - in the auditory modality — can be seen in Ramachandran et al 1996). It was also expected that the main differences between controls and HR subjects would appear in these regions, with lower positive or more negative current sources at centroparietal and frontocentral areas in HR subjects than in control subjects.

The low component amplitudes observed in the HR subjects suggest that current sources extend from central to parietal and right temporal areas in the control group, but appear somewhat weaker and less widespread in the HR group. The children of alcoholics, however, demonstrated two sinks in middle and right positions of the frontal area that did not appear in the control subjects. In the occipital region, a sink appeared in the control subjects CSD map but was absent in the HR group's CSD map. The main group differences in the CSD maps appeared primarily in the sinks at the frontal and occipital areas with some extension into the centroparietal sources. Thus, the widespread scalp distribution differences suggest that multiple cortical structures were involved in ERP generation.

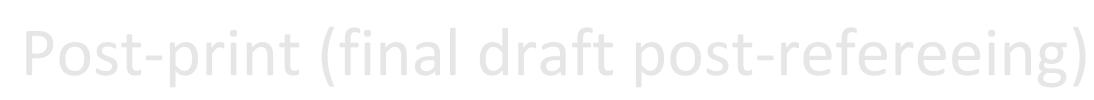


In this context, it is interesting to note that several areas appear to underlie a limbic-cortical network for novelty detection and orientation of attention that are also thought to contribute to P3a generation (Mesulam 1990; Knight 1996, 1997). Human intracranial recordings and ERP studies of lesioned patients have indicated frontal lobe contributions (Knight 1984, 1997; Baudena et al 1995), posterior association (temporoparietal junction, lateral parietal lobe) cortex (Halgren et al 1995a,b; Knight 1997), as well as limbic structures (posterior hippocampus, parahippocampal region, cingulate gyrus, medial temporal lobe) (Halgren et al 1995a,b; Knight 1996). Future studies complementing the ERP evaluations with neuroimaging techniques will help determine which of these structures, and perhaps other subcortical areas, are involved in the electrophysiologic dysfunction observed in HR subjects.

\section{Theoretical Interpretation}

The present results provide neurophysiologic support for the hypothesis that the subjects at risk for alcoholism demonstrate processing dysfunction for intrusive events (Pihl et al 1990; Sher 1991), because no evidence for central indices of the orienting response in HR subjects has been previously reported. The mismatch negativity (MMN), an earlier ERP component related to the automatic processing of infrequent unattended auditory stimuli, are inconsistent in their findings, with one study reporting no differences between young HR and control subjects and another reporting increased amplitude in an adult HR group (Van der Stelt et al 1997; Zhang et al unpublished data). The P3a component elicited in the present study by an infrequent non-target stimulus that disrupts a perceptually difficult discrimination task produced anomalous reduction in HR adult subjects. Taken together with behavioral impulsivity or attention deficits that are also risk factors for alcoholism, studies that incorporate ERPs with behavioral and neuropsychological assays appear to be highly warranted.

Positive ERP waves have been related to inhibition of cortical neuronal networks (Birbaumer et al 1990), and this inhibitor disfacilitation of surrounding regions is necessary to limit cortical excitation to task specific areas (Woodward et al 1991; Rockstroh et al 1992; Schupp et al 1994; Rockstroh et al 1996). Hence, the reduced amplitude of P3a may indicate a dysfunction in the neuronal modulation necessary for an adequate processing of novel events, suggesting a deficit in neuronal inhibition. Because both P3b and P3a are anomalous in subjects at risk for alcoholism, however, commonalities between these components should be explored to clarify the genesis of the underlying neurofunctional abnormalities. P3b has been related to the recognition of a stimulus relevant to the task, and the significance of the stimulus for the task has a major influence in the definition of P3b (Donchin et al 1986; Johnson 1986). P3a has been related to the orienting toward an irrelevant stimulus that attracts the attention focused in the task (Katayama and Polich 1998). The two components have common features: 1) both P3a and P3b are determined most strongly by the context and moderately by the physical characteristics of the stimulus; 2) both components are similarly affected by stimulus probability; 3 ) the components overlap each other (Polich 1988); and 4) they appear to share common neural generators (Baudena et al 1995; Halgren et al 1995a, b). Taken in context with the theoretical interpretation given above, it is reasonable to suppose that the $\mathrm{P} 3 \mathrm{a}$ and $\mathrm{P} 3 \mathrm{~b}$ amplitude reductions are related to a deficit in the neuronal inhibition occurring during the comparison of infrequent stimuli with a memory template, necessary for an adequate processing of all the infrequent stimuli in the task. 
Deficits in inhibition were suggested by the behavioral data. The shorter (although nonsignificant) response time ( $\mathrm{RT})$ in the HR subjects $(\mathrm{RT}=515 \mathrm{msec}$ ) compared with controls ( $\mathrm{RT}=599 \mathrm{msec}$ ) lead us to hypothesize that HR subjects were also less able to inhibit their responses. This could lead both to shorter RTs and to pressing the button even when in doubt. On the other hand, the controls, more able to control behavior, would try to avoid false alarms, inhibiting their responses in doubtful cases, and resulting in a higher percentage of missed targets. This explanation based on a lack of behavioral inhibition would be supported by the relatively high percentage of false alarms to the easily discriminable infrequent non-target in the HR group (HR $=2.1 \%$; $\mathrm{CN}=$ $0.8 \%$ ); however, this difference did not reach statistical significance either.

Thus, the behavioral data could be explained within the framework of problems in behavioral inhibition frequently associated with high risk for alcoholism (see Sher 1991, chapter 6) and that could be associated with deficits in the neuronal inhibition indicated by the ERP studies. Nonetheless, the fact that differences in response time and false alarms to the well-differentiated infrequent nontarget did not reach significance leads us to be cautious in offering this explanation. Perhaps with larger sample sizes, these intriguing behavioral data would reach significance.

\section{Conclusions}

Finally, the reduced P3a amplitudes observed in HR subjects in the present study agree with ERP findings from abstinent alcoholics using the same paradigm (Rodríguez Holguín et al 1999), where affected individuals also produced diminished P3a voltages. Although HR subjects drank more heavily than controls, this variable may not explain the ERP differences, as alcohol consumption was controlled using it as a covariate. Hence, P3a amplitude satisfies some of the conditions necessary for a phenotypic marker of a psychiatric disease (Begleiter and Porjesz 1995): It is present in patients during symptom remission, occurs among first-degree relatives of affected subjects at a rate higher than that of the normal population, and although the P3b is reliable as a measure of genetic transmission, this attribute has not yet been established for the P3a. The present study found widespread reduced visual P3a amplitudes in adult male subjects at HR for alcoholism when a well-differentiated stimulus is infrequently inserted in a perceptually difficult discrimination task. These results support that automatic processing of infrequent irrelevant stimuli is not readily accomplished in HR subjects. Further studies are required to replicate these findings with independent samples, assess outcomes in other stimulus modalities, and apply them to female subjects samples.

This research was supported by NIH Grants AA08401 and AA08403. Dr. Holguin is a Visiting Research Fellow at the Department of Psychiatry, State University of New York Health Science Center, supported by the Galician Government Research Authority (DOG 08/26/ 1997).

The Collaborative Study on the Genetics of Alcoholism (H. Begleiter, SUNY Health Science Center at Brooklyn, Principal Investigator; Ted Reich, Washington University, Co-Principal Investigator) includes six different centers where data collection takes place. The six sites and principal investigator and co-investigators are: Indiana University (J. Nurnberger Jr., P.M. Conneally); University of Iowa (R. Crowe, S. Kuperman); University of California at San Diego and Scripps Institute (M. Schuckit, F. Bloom); University of Connecticut (V. Hesselbrock); State 
University of New York, Health Science Center at Brooklyn (B. Porjesz, H. Begleiter);Washington University in St. Louis (T. Reich, C.R. Cloninger).

We would like to thank Brian Beckrich, Tao Chang, Lisa Iskander, Vladimir Kotlyarevsky, Arthur Stimus, Hanbi Ye, and Sergio Valentini for their invaluable technical assistance.

\section{References}

Almasy L, Porjesz B, Blangero J, Chorlian DB, O'Connor SJ, Polich J, et al (in press): Heritability of the P300 and N100 components of the event-related brain potential in families with a history of alcoholism. Neuropsychiatric Genet.

American Electroencephalographic Society (1991): American Electroencephalographic Society guidelines for standard electrode position nomenclature. J Clin Neurophysiol 8:200 -202.

Baribeau J, Ethier M, Braun CMJ (1987): Neurophysiological assessment of selective attention in males at risk for alcoholism. In: Johnson R, Rohrbaugh JW, Parasuraman R, editors. Current Trends in Event-Related Potential Research (EEG, Suppl. 40). Amsterdam: Elsevier, pp 651-656.

Baudena P, Halgren E, Heit G, Clarke JM (1995): Intracerebral potentials to rare target and distractor auditory and visual stimuli. III. Frontal cortex. Electroenceph Clin Neurophysiol 94:251-264.

Bauer LO, Hesselbrock VM, O'Connor S, Roberts L (1994a): P300 differences between non-alcoholic young men at average and above-average risk for alcoholism: Effects of distraction

and task modality. Progr Neuropsychopharmacol Biol Psychiatry 18:263-277.

Bauer LO, O'Connor S, Hesselbrock VM (1994b): Frontal P300 decrements in antisocial personality disorder. Alcohol Clin Exp Res 18:1300 -1305.

Begleiter H, Porjesz B (1995): Neurophysiological phenotypic factors in the development of alcoholism. In: Begleiter H, Kissin B, editors. Alcohol and Alcoholism. Vol. 1. The Genetics of Alcoholism. New York: Oxford University Press, pp 269-293.

Begleiter H, Porjesz B, Bihari B, Kissin B (1984): Event-related brain potentials in boys at risk for alcoholism. Science 225:1493-1496.

Begleiter H, Porjesz B, Rawlings R, Eckardt M (1987): Auditory recovery function and P3 in boys at risk for alcoholism. Alcohol 4:315-321.

Begleiter H, Porjesz B, Wang W (1993): A neurophysiological correlate of visual short-term memory in humans. Electroenceph Clin Neurophysiol 87:46 -53.

Benegal V, Janin S, Subbukrishna DK, Channabasavana SM (1995): P300 amplitudes vary inversely with continuum of risk in first degree male relatives of alcoholics. Psychiatry Genet 5:149 -156.

Berman SM, Martı'nez RA, Noble EP (1993a): Familial alcoholism and ERPs: Differences in probability sensitivity? Alcohol Alcohol 28:695-707.

Berman SM, Whipple SC, Fitch RJ, Noble EP (1993b): P3 in young boys as predictor of adolescent substance use. Alcohol 10:69 -76.

Biggins CA, MacKay S, Clark W, Fein G (1997): Event-related potential evidence for frontal cortex effects of chronic cocaine dependence. Biol Psychiatry 42:472- 485.

Biggins CA, MacKay S, Poole N, Fein G (1995): Delayed P3a in abstinent elderly male chronic alcoholics. Alcohol Clin Exp Res 19:1032-1042.

Birbaumer N, Elbert T, Canavan AGM, Rockstroh B (1990): Slow potentials of the cerebral cortex and behavior. Physiol Rev 70:1-41. 
Bucholz KK, Cadoret R, Cloninger CR, Dinwiddie SH, Hesselbrock VM, Nurnberger JI Jr et al (1994): A new, semistructured psychiatric interview for use in genetic linkage studies: A report of the reliability of the SSAGA. J Stud Alcohol 55:149-158.

Chorlian DB, Porjesz B, Cohen HL (1995): Measuring electrical activity of the brain: ERP mapping in alcohol research. Alcohol Health Res World 19:315-320.

Cohen HL, Porjesz B, Begleiter H, Wang W (1997): Neuroelectric correlates of response production and inhibition in individuals at risk to develop alcoholism. Biol Psychiatry 42:57-67.

Cohen HL, Wang W, Porjesz B, Begleiter H (1995): Auditory P300 in young alcoholics: Regional response characteristics. Alcohol Clin Exp Res 19:469-475.

Comerchero MD, Katayama J, Polich J (1997): P3a and P3b from auditory and visual stimuli. Psychophysiology 34:S27.

Comerchero MD, Polich J (1998): P3a, perceptual distinctiveness, and stimulus modality. Cognitive Brain Res 7:41-48.

Comerchero MD, Polich J (1999): P3a and P3b from typical auditory and visual stimuli. Electroenceph Clin Neurophysiol 110:24 -30.

Courchesne E (1977): Event-related brain potentials: Comparison between children and adults. Science 197:589-592.

Courchesne E (1978): Neurophysiological correlates of cognitive development: Changes in long-latency even-related potentials from childhood to adulthood. Electroenceph Clin Neurophysiol 45:468482.

Courchesne E (1983): Cognitive components of the event-related brain potential: Changes associated with development. In: Gaillard AWK, Ritter W, editors. Tutorials in Event-Related Potential Research: Endogenous Components. Amsterdam: North Holland, pp 329-344.

Courchesne E, Hillyard SA, Galambos R (1975): Stimulus novelty, task relevance and the visual evoked potentials in man. Electroenceph Clin Neurophysiol 39:131-143.

Donchin E, Karis D, Bashore TR, Coles MGH, Gratton G (1986): Cognitive psychophysiology and human information processing. In: Coles MGH, Donchin E, Porges SW, editors. Psychophysiology: Systems, Processes and Applications. New York: The Guilford Press, pp 244-267.

Eischen SE, Polich J (1994): P300 from families. Electroenceph Clin Neurophysiol 92:369 -372.

Elmasian R, Neville H, Woods D, Schuckit M, Bloom FE (1982): Event-related brain potentials are different in individuals at high and low risk for developing alcoholism. Proc Nal Acad Sci 79:7900 $-7903$.

Finn PR, Zeitouni NC, Pihl RO (1990): Effects of alcohol on psychophysiological hyperreactivity to nonaversive and aversive stimuli in men at high risk for alcoholism. $J$ Abn Psychol 99:79-85.

Gevins A, Le J, Brickett P, Reuter B, and Desmond J (1991):Seeing through the skull: Advanced EEGs using MRIs to accurately measure cortical activity from the scalp. Brain Topogr 4:125-131.

Glenn SW, Sinha R, Parsons OA (1993): Electrophysiological indices predict resumption of drinking in sober alcoholics. Alcohol 10:89 -95.

Halgren E, Baudena P, Clarke JM, Heit G, Lie'gelois C, Chauvel P et al (1995a): Intracerebral potentials to rare target and distractor auditory and visual stimuli. II. Medial, lateral and posterior temporal lobe. Electroenceph Clin Neurophysiol 94:229 -250.

Halgren E, Baudena P, Clarke JM, Heit G, Marinkovic K,Devaux B, et al (1995b): Intracerebral potentials to rare target and distractor auditory and visual stimuli. II. Medial, lateral and posterior temporal lobe. Electroenceph Clin Neurophysiol 94:229 -250. 
Hesselbrock VM (1995): The genetic epidemiology of alcoholism. In: Begleiter H, Kissin B, editors. The Genetics of Alcoholism. New York: Oxford University Press, pp 17-39.

Hesselbrock VM, Bauer LO, O'Connor S, Gillen R (1993): Reduced P300 amplitude in relation to family history of alcoholism and antisocial personality disorder among young men at risk for alcoholism. Alcohol Alcohol Suppl. 2:95-100.

Hill SY, Steinhauer SR (1993): Assessment of prepubertal and postpubertal boys and girls at risk for developing alcoholism with P300 from a visual discrimination task. J Stud Alcohol 54:350 -358.

Hill SY, Steinhauer SR, Lowers L, Locke J (1995): Eight-year longitudinal follow-up of P300 and clinical outcome in children from high risk for alcoholism families. Biol Psychiatry 37:823-827.

Hill SY, Steinhauer SR, Park J, Zubin J (1990): Event-related potential characteristics in children of alcoholics from high density families. Alcohol Clin Exp Res 14:6 -16.

Johnson R (1986): A triarchic model of P300 amplitude. Psychophysiology 23:367-384.

Katayama J, Polich J (1996a): P300 from one-, two-, andthree-stimulus auditory paradigms. Int J Psychophysiol 23: 33-40.

Katayama J, Polich J (1996b): P300 probability, and the threetone paradigm. Electroenceph Clin Neurophysiol 100:555- 562.

Katayama J, Polich J (1998): Stimulus context determines P3a and P3b. Psychophysiology 35:23-33.

Katsanis J, Iacono WG, McGue MK, Carlson SR (1997): P300 event-related potential heritability in monozygotic and dizygotic twins. Psychophysiology 34:47-58.

Knight RT (1984): Decreased response to novel stimuli after prefrontal lesions in man. Electroenceph Clin Neurophysiol 59:9-20.

Knight RT (1996): Contribution of human hippocampal region to novelty detection. Nature 383:256 259.

Knight RT (1997): Distributed cortical network for visual attention. J Cogn Neurosci 9:75-91.

Mesulam MM (1990): Large-scale neurocognitive networks and distributed processing for attention, language, and memory. Ann Neurol 28:597-613.

Newlin DB, Thomson JB (1991): Chronic tolerance and sensitization to alcohol in sons of alcoholics. Alcohol Clin Exp Res 15:399-405.

Nunez PL, Pilgreen KL (1991): The spline-Laplacian in clinical neurophysiology: A method to improve EEG spatial resolution. J Clin Neurophysiol 8:397-413.

O'Connor S, Bauer L, Tasman A, Hesselbrock VM (1994a): Reduced P3 amplitudes are associated with both a family history of alcoholism and antisocial personality disorder. Prog Neuropsychopharmacol Biol Psychiatry 18:1307-1321.

O'Connor S, Hesselbrock VM, Tasman A (1986): Correlates of increased risk for alcoholism in young men. Prog Neuropsychopharmacol Biol Psychiatry 10:211-218.

O’Connor S, Hesselbrock VM, Tasman A, DePalma N (1987): P3 amplitudes in two distinct tasks are decreased in young men with a history of paternal alcoholism. Alcohol 4:323-330.

O'Connor S, Morzorati S, Christian JC, Li T-K (1994b): Heritable features of the auditory oddball eventrelated potential: Peaks, latencies, morphology and topography. Electroenceph Clin Neurophysiol 92:115-125.

Parsons OA (1994): Neuropsychological measures and eventrelated potentials in alcoholics: Interrelationships, long-term reliabilities, and prediction of resumption of drinking. J Clin Psychol 50:37- 46 . 
Pfefferbaum A, Ford JM, White PM, Mathalon D (1991): Event-related potentials in alcoholic men: P3 amplitude reflects family history but no alcoholic consumption. Alcohol Clin Exp Res 15:839850.

Pihl RO, Finn PR, Peterson JB (1989): Autonomic hyperreactivity and risk for alcoholism. Prog Neuropsychopharmacol Biol Psychiatry 13:489-496.

Pihl RO, Peterson JB, Finn PR (1990): Inherited predisposition to alcoholism: Characteristics of sons of male alcoholics. J Abn Psychol 99:291-301.

Polich J (1988): Bifurcated P300 peaks: P3a and P3b revisited? J Clin Neurophysiol 5:287-294.

Polich J, Bloom FE (1986): P300 and alcohol consumption in normals and individuals at risk for alcoholism: A preliminary report. Prog Neuropsychopharmacol Biol Psychiatry 10:201-210.

Polich J, Bloom FE (1987): P300 from normal adult children of alcoholics. Alcohol 4:301-305.

Polich J, Burns T (1987): P300 from identical twins. Neuropsychologia 25:299 -304.

Polich J, Burns T, Bloom FE (1988a): P300 and the risk for alcoholism: Family history, task difficulty and gender. Alcohol Clin Exp Res 12:248 -254.

Polich J, Haier RJ, Buchsbaum M, Bloom FE (1988b): Assessment of young men at risk for alcoholism with P300 from a visual discrimination task. J Stud Alcohol 49:186 -190.

Polich J, Kok A (1995): Cognitive and biological determinants of P300: An integrative review. Biol Psychol 41:103-146.

Polich J, Pollock VE, Bloom FE (1994): Meta-analysis of P300 amplitude from males at risk for alcoholism. Psychol Bull 115:55-73.

Porjesz B, Begleiter H (1985): Human brain electrophysiology and alcoholism. In: Tarter RD, Van Thiel D, editors. Alcohol and the Brain. New York: Plenum Press, pp 139-182.

Porjesz B, Begleiter H (1990): Event-related potentials in individuals at risk for alcoholism. Alcohol 7:465- 469 .

Porjesz B, Begleiter H (1996): Effects of alcohol on electrophysiological activity of the brain. In: Begleiter H, Kissin B, editors. Alcohol and Alcoholism. Vol. 2. The Pharmacology of Alcohol and Alcohol Dependence. New York: Oxford University Press, pp 207-247.

Ramachandran G, Porjesz B, Begleiter H, Litke A (1996): A simple auditory oddball task in young adult males at risk for alcoholism. Alcohol Clin Exp Res 20:9-15.

Realmuto G, Begleiter H, Odencrantz J, Porjesz B (1993): Event-related potential evidence of dysfunction in automatic processing in abstinent alcoholics. Biol Psychiatry 33:594-601.

Rockstroh B, Muller M, Cohen R, Elbert T (1992): Probing the functional brain state during P300evocation. J Psychophysiol 6:175-184.

Rockstroh B, Muller M, Heinz A, Wagner M, Berg P, Elbert T (1996): Modulation of auditory responses during oddball tasks. Biol Psychol 43:41-55.

Rodríguez Holguín S, Corral M, Cadaveira F (1998a): Eventrelated potentials elicited by infrequent nontarget stimuli in young children of alcoholics: Family history and gender differences. Alcohol Alcohol 33:281-290.

Rodríguez Holguín S, Corral M, Cadaveira F (1998b): Visual and auditory event-related potentials in young children of alcoholics from high and low density families. Alcohol Clin Exp Res 22:87-96.

Rodrí́guez Holguín S, Porjesz B, Chorlian DB, Polich J, Begleiter H (1999): Visual P3a in male alcoholics and controls. Alcohol Clin Exp Res 23:582-591.

Rogers TD, Deary I (1991): The P300 component of the auditory event-related potential in monozygotic and dizygotic twins. Acta Psychiatr Scand 83:412- 416. 
Schandler SL, Cohen MJ, Antick JR (1992): Activation, attention, and visuospatial learning in adults with and without a family history of alcoholism. Alcohol Clin Exp Res 16:566-571.

Schupp HT, Lutzenberg W, Rau H, Birbaumer N (1994): Positive shifts of event-related potentials: A state of cortical disfacilitation as reflected by the startle reflex probe. Electroenceph Clin Neurophysiol 90:135-144.

Sharma A, Malhotra S, Raghunathan M, Malhotra A (1997): A study of event-related potential: P3 characteristics in children of alcoholics. Addiction Biol 2:431- 438.

Sher KJ (1991): Children of Alcoholics. A Critical Appraisal of Theory and Research. Chapter 6 Biological Characteristics. Chicago: University of Chicago Press, pp 72-92.

Squires NK, Squires KC, Hillyard SA (1975): Two varieties of long-latency positive waves evoked by unpredictable auditory stimuli in man. Electroenceph Clin Neurophysiol 38:387- 401.

Srebro R (1996): A bootstrap method to compare the shapes of two scalp fields. Electroenceph Clin Neurophysiol 100:25- 32.

Steinhauer SR, Hill SY (1993): Auditory event-related potentials in children at high risk for alcoholism. J Stud Alcohol 54:408-421.

Steinhauer SR, Hill SY, Zubin J (1987): Event-related potentials in alcoholics and their first-degree relatives. Alcohol 4:307-314.

Van Beijsterveldt CEM, Boomsma DI (1994): Genetics of the human electroencephalogram (EEG) and event-related potentials (ERPs): A review. Hum Genet 94:319-330.

Van der Stelt O, Gunning WB, Snel J, Kok A (1996): Children of alcoholics: Brain potentials associated with novelty. Alcohol Clin Exp Res 20:34A.

Van der Stelt O, Gunning WB, Snel J, Kok A (1997): No electrocortical evidence of automatic mismatch dysfunction in children of alcoholics. Alcohol Clin Exp Res 21:569 -575.

Whipple SC, Berman SM, Noble EP (1991): Event-related potentials in alcoholic fathers and their sons. Alcohol 8:321- 327.

Whipple SC, Noble EP (1986): The effects of familial alcoholism on visual event-related potentials. Psychophysiology 23:470.

Whipple SC, Parker ES, Noble EP (1988): An atypical neurocognitive profile in alcoholic fathers and their sons. J Stud Alcohol 49:240 -244.

Woodward S, Brown W, Marsh J, Dawson M (1991): Probing the time-course of the auditory oddball P3 with secondary reaction time. Psychophysiology 28:609-618.

Zhang XL, Begleiter H, Porjesz B, Litke A (1997): Visual object priming differs from visual word priming: An ERP study. Electroenceph Clin Neurophysiol 102:200 -215. 
Table 1. Demographic Characteristics of Control and HighRisk Groms

\begin{tabular}{|c|c|c|c|c|}
\hline & \multicolumn{2}{|c|}{$\begin{array}{c}\text { Coutrol gor } \\
(n=23)\end{array}$} & \multicolumn{2}{|c|}{$\begin{array}{c}\text { High-rik grou } \\
(n=25)\end{array}$} \\
\hline & Man & SD & Masu & SD \\
\hline $\begin{array}{l}\text { Age (your) } \\
\text { Etwation (yor) }\end{array}$ & $\begin{array}{l}24.6 \\
15.7\end{array}$ & $\begin{array}{l}3.2 \\
2.4\end{array}$ & $\frac{228}{121}$ & $\begin{array}{l}13 \\
13\end{array}$ \\
\hline Drinking dynimouth & 2.1 & 2.7 & 63 & 51 \\
\hline Chinluboriso & 1.7 & 1.7 & 47 & 44 \\
\hline
\end{tabular}

Table 2. Behavioral Data for Control and High-Risk Groups

\begin{tabular}{|c|c|c|c|c|}
\hline & \multicolumn{2}{|c|}{$\begin{array}{c}\text { Control grop } \\
(n=23)\end{array}$} & \multicolumn{2}{|c|}{$\begin{array}{c}\text { High-rik gou } \\
(n=26)\end{array}$} \\
\hline & Max & $5 \mathrm{D}$ & Man & $3 D$ \\
\hline Rorpans time (mas) & 99 & 1237 & 515 & 715 \\
\hline Carnet $(H)$ & 689 & 14.6 & 83.6 & 115 \\
\hline Fals alsm $(9)$ & 4.1 & 59 & 4.5 & 54 \\
\hline
\end{tabular}




\section{Infrequent Non-Target ERPs}
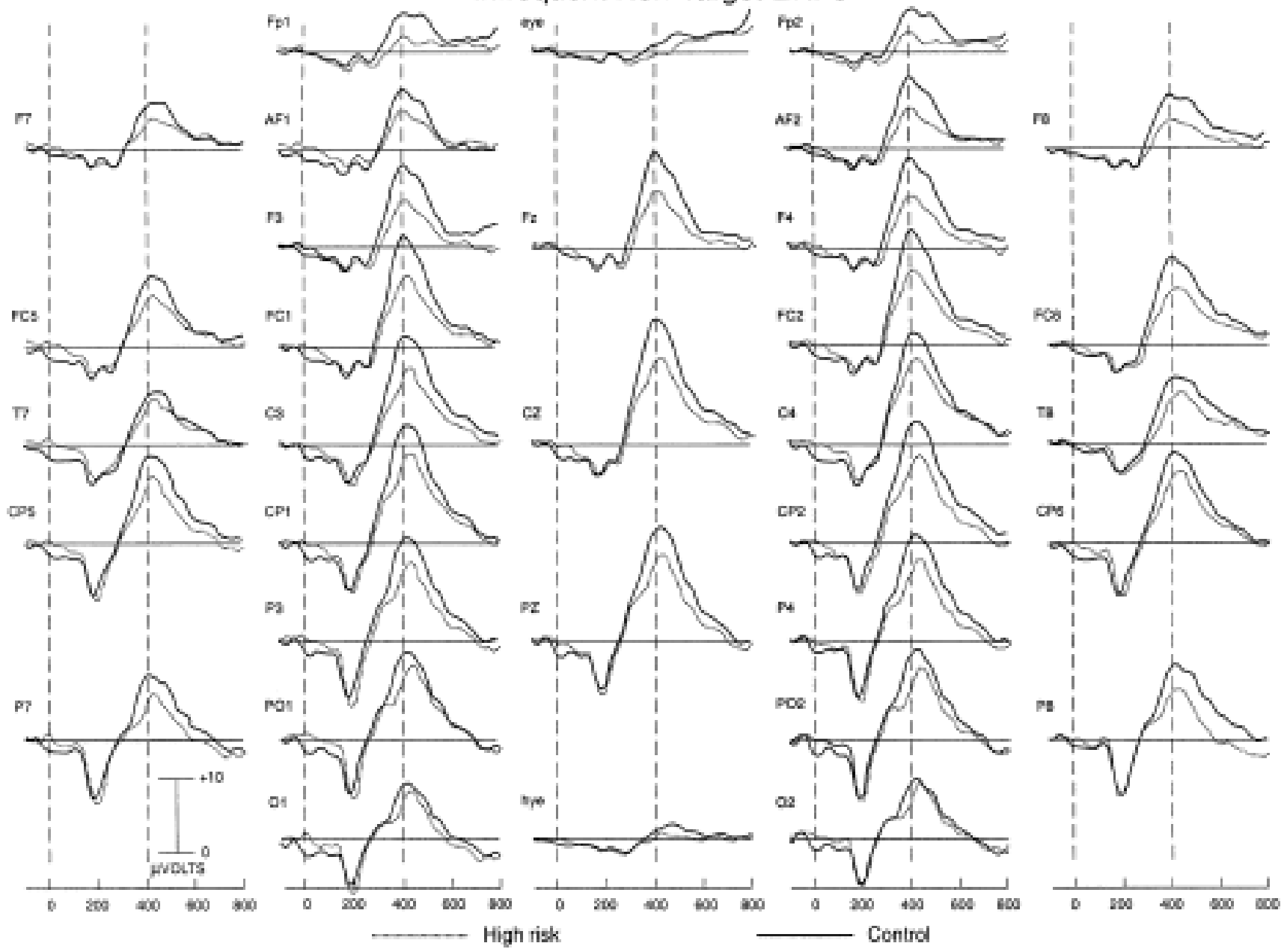

Figure 1. Grand mean waveforms of the ERPs for the control $(n-23)$ and the high-risk $(n-26)$ groups.

\section{Post-print (final draft post-refereeing)}


Table 3. Mean P3a Anplitudes ( $\mu$ V) for Infrequent Nontarget Stimulus in the Control and HighRisk Groups

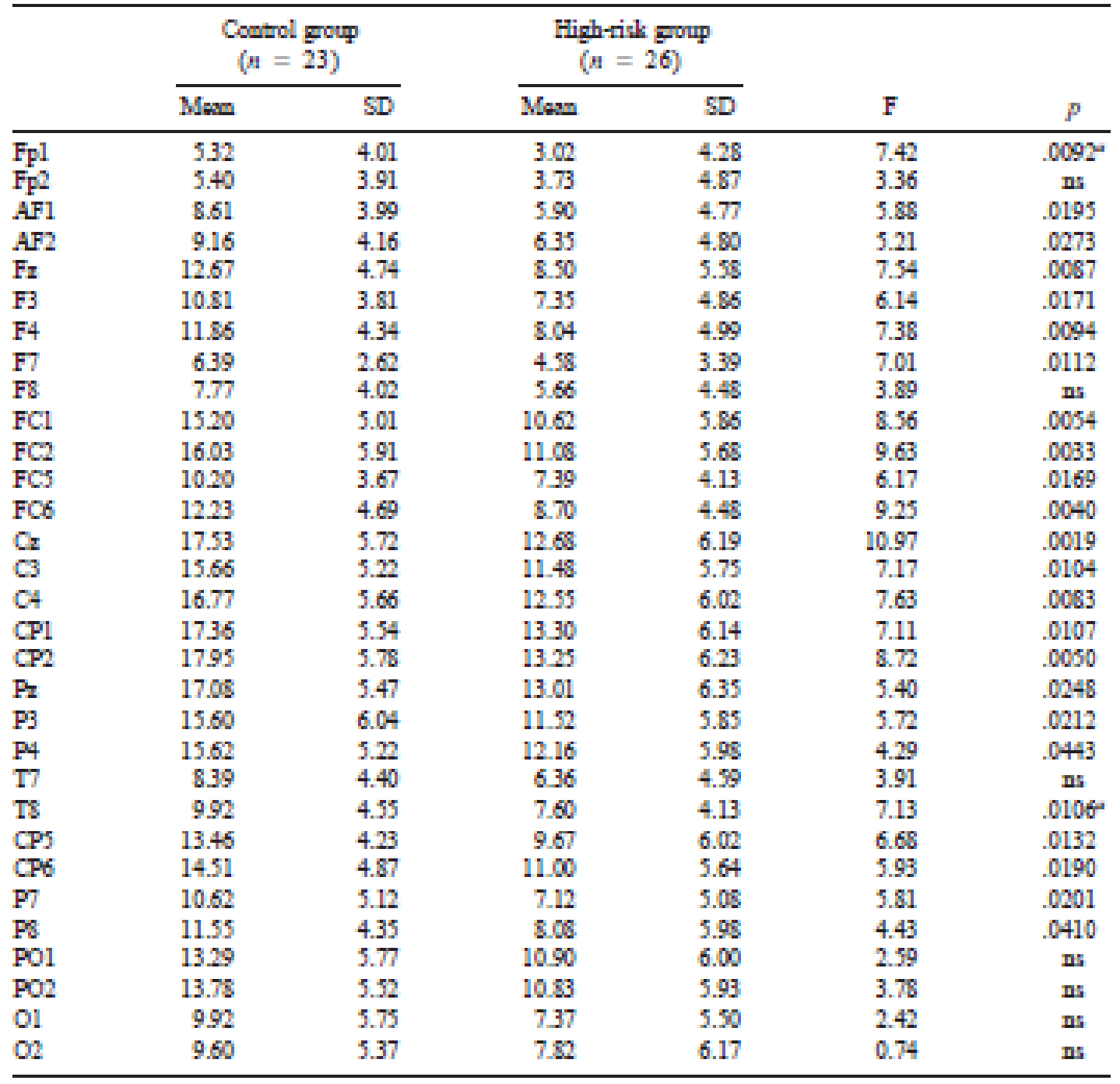

Af $(1,44)$

tho significant Bonfenoti osenperise. 


\subsection{0
20.0
10.0
0.0
-10.0
-20.0}

(1)

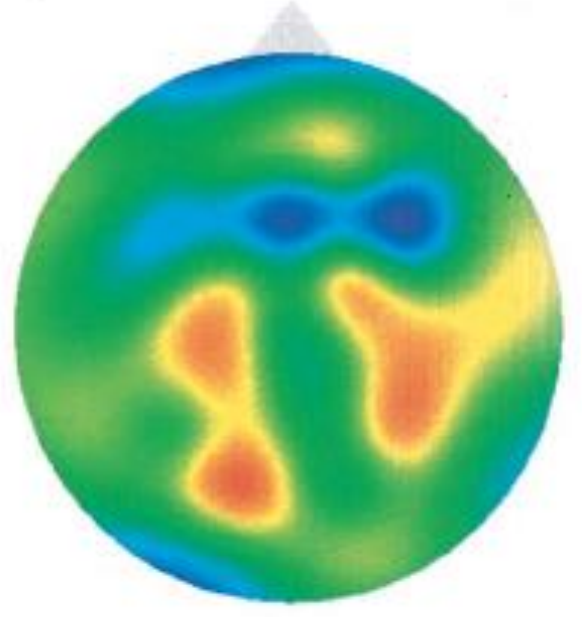

HIGH RISK

Figure 2. CSD maps at the P3a penk for control ( $402 \mathrm{msec}$ ) and high-risk ( $430 \mathrm{msec}$ ) groups (the scale uses arbitrary units). 